\title{
Characterization of Bacillus thuringiensis strains under the umbrella of a Brazil- Cuba cooperation on bioinsecticides
}

\author{
Y. Baró R. ${ }^{1}$, M.E. Marques ${ }^{1}$, D. M. F. Capalbo ${ }^{2}$, I. S. Melo ${ }^{2}$, Orietta Larrea-Vega ${ }^{1}$, I. O. Moraes ${ }^{3}$ \\ ${ }^{1}$ Instituto de Investigaciones de Sanidad Vegetal - INISAV, Calle 110, N. 514e/ 5ta B y 5ta F, Municipio Playa. Havana, \\ Cuba. Código Postal 11600. \\ ${ }^{2}$ Embrapa Environment, CP69, CEP 13820-000, Jaguariuna/SP, Brazil. \\ ${ }^{3}$ Probiom Ltda., R. Latino Coelho, 1301, Prédio 5, CEP 13087-010, Campinas/SP, Brazil
}

Bacillus thuringiensis (Bt) is a sporogenic bacterium that produces characteristic crystalline inclusions (Cry proteins), during sporulation. Each strain shows its specific activity against larvae of different insect and also some nematode pests. Because of its specificity, $B t$ has been widely recommended for biological pest control. Even with the development of genetically modified plants, that could produce Bt-activated toxins, the screening of new toxic $B t$ species is still needed, looking especially for active species against the most resistant pests. A technical cooperation program Brazil-Cuba, funded by the Brazilian Council for Scientific and Technological Development (CNPq), supported studies in order to characterize new $B t$ strains of Brazil and Cuba interest.

In this work, the crystal morphology and Cry protein composition of twelve Bt strains, isolated from Cuban environment and maintained at INISAV Culture Collection, were analyzed. Their biological activities were evaluated in vitro against Spodoptera frugiperda (a very aggressive insect and also very resistant to the $B t$ toxin), Anticarsia gemmatalis (very sensitive to Bt toxin), and eggs of the nematode Meloidogyne incognita. Brazilian and Cuban methodologies for bioassay were utilized, integrating efforts and expertise of both countries.

The insect bioassays showed that two $B t$ strains were highly active against $S$. frugiperda and $A$. gemmatalis $(100 \%$ mortality within $48 \mathrm{~h})$, while eight showed activity just against $A$. gemmatalis, and two showed no activity at all.

Regarding nematicidal effects, six strains interrupted the development of egg masses, some of which appeared necrotic. There were different behaviors regarding nematode infectivity after treatment with each $B t$ strain, but all treatments resulted in nematostatic and disorientation effects with a marked reduction of the nematode infectivity, under the experimental conditions.

Regarding the Cry protein profile by SDS-PAGE, most of the strains showed proteins of $130 \mathrm{kDa}$ and $70 \mathrm{kDa}$, and one of them showed just proteins of $130 \mathrm{kDa}$.

The scanning electron micrographies as well as the morphology, size and number of the inclusions showed variations amongst the different $B t$ strains, as expected. Literature shows that the morphology of $B t$ crystals is not an absolute indicator of its insecticidal activity but, instead, represents an important criteria for characterization of a new strain. Bipyramidal and cubic inclusions were observed in the strains tested.

Based on the results obtained the two most virulent strains against insects and the most promissory nematicidal (at least two) will be further studied for mass production and formulation as a biopesticide. Further studies will be developed in order to clarify if the nematicidal activity could be attributed to a specific fraction (supernatant/precipitated; thermostable / thermosensitive) of the fermentation broth. 